\title{
Power of Regenerative Braking with Kinetic Energy Recovery System
}

\author{
M. E. Ramadhan ${ }^{1}$ and Harus L.G. ${ }^{2}$
}

\begin{abstract}
Braking and acceleration is often carried out by the driver on the highway with heavy traffic intensity. This leads to a lack of effective implementation of the Kinetic Energy Recovery System (KERS) on urban vehicles, because of the relatively short time braking and discontinued. Research results show that the braking process resulted in a 15-20\% loss of energy of the fuel energy combustion engine. To restore the energy loss due to braking, kinetic energy recovery methods developed in excess of a vehicle are often called Kinetic Energy Recovery System (KERS). In this research, experimental study of the influence of variations in speed changes just before braking on the characteristics of KERS. To realize this experimental study, conducted engineering process simple mechanism incorporating KERS braking system comprising, $1.82 \mathrm{~kg}$ mass flywheel and generator $12 v o l t$ voltage, 800watt maximum power. Experiment begins with analyzing the flywheel kinetic energy generated by setting VSD (Variable Speed Drive) 10hz, 15hz, 20hz and 25hz, then at each end of the round setting made braking. The next experiment is done by finding the speed variation characteristics of KERS just before braking, braking then performed to determine the change of electrical energy that can be raised KERS. This paper result efficiency power of regenerative braking with kinetic energy recovery system in laboratory scale. Based on observations made on 50Ah 12 volt battery charging, electrical mechanical KERS apparently capable of producing an average 14.07volt, the average current 5.078ampere and average power electrical energy 71.3 watt. The result show charging capacity is still small round duration at 3015.5rpm 6.88second produce 95mAh and efficiency of KERS at 1197rpm 119\%, 1816rpm 75\%, 2229rpm 60\% and 2766rpm 53\%.
\end{abstract}

Keywords—Regenerative Braking System (RBS), Kinetic Energy Recovery System (KERS), Electric Power Recovery.

\section{INTRODUCTION}

$\mathrm{F}$ lywheel energy recovery system is a system that consists of a flywheel, transmission, generator equipped with IC regulators, and electric energy storage system. The size of the kinetic energy is influenced by the prime movers rotary flywheel moment, then of material, geometry cross-sectional shape, length and bearing flywheel is used. At this time the research with considering safety factor and the losses in the form of friction, obtained by $200 \mathrm{wh} / \mathrm{kg}$ specific energy and specific power $30 \mathrm{KW} / \mathrm{kg}$ [4]. To the mechanism of variator transmission KERS as a form of DFTV, SHTV and SFTV has done simulation and testing of the efficiency. That DFTV and SHTV have better efficiency in $10 \%$ of SFTV [5]. However, making the transmission costs are very expensive and that it provides maximum 6:1 ratio.

KERS is a system that is very easy and can be used all vehicle, the following are some of the applications and the analysis of the KERS energy generation, such as analysis of specific energy and power generated is stored in the battery when on the train ride off and running conditions [3]. Then the electric bus mathematical modeling is used to analyze the energy consumption and performance kers based trip with these styles influence motion force, torque, power and motor speed. Then analyzed the kinetic energy generation [1]. Then simulated braking with the validation of the prototype of a conventional vehicle that is modified into an electric vehicle. The braking system in the form of a conventional braking system, abs braking and braking system with pressure distribution on each master cylinder respectively. Results of validation states that for

${ }^{1}$ M. E. Ramadhan is with Departement of Mechanical Engineering, Faculty of Engineering, Universitas Jember, Jember, 68121, Indonesia E-mail: edowarditsdesain@gmail.com.

${ }^{2}$ Harus L.G is with Departement of Mechanical Engineering, Faculty of Industrial Technology, Institut Teknologi Sepuluh Nopember, Surabaya, 60111, Indonesia. E-mail: harus_lg@me.its.ac.id. conventional braking energy generation $52 \mathrm{Wh}$ within $4.1 \mathrm{~s}$, the pressure distribution on the master cylinder 58 wh each within $4.2 \mathrm{~s}$ and for abs $67 \mathrm{wh}$ within $5.2 \mathrm{~s}$ [6].

Braking and acceleration is often carried out by the driver on the highway with heavy traffic intensity. This leads to a lack of effective implementation of the Kinetic Energy Recovery System (KERS) on urban vehicles, because of the relatively short time braking and discontinued. Based on the research that has been done that the braking process the amount of energy wasted by $15-20 \%$ of the energy produced in the fuel combustion engine. In the present study, to determine the design of complex designs that KERS will do experiments with characteristics are influenced by variations in the speed of change just before braking. So from this study are expected to know the working principle of a simple electrical mechanical KERS mechanism that could restore the wasted kinetic energy using 4:1 nonvariator transmission belt that is used to turn a generator 12 volt 45 Ampere, and inertia flywheel $0.0845 \mathrm{~kg} . \mathrm{m}^{2}$.

\section{METHOD}

First step, calibrating generator voltage to converted angular velocity sensor with tachometer. Source of voltage generator applies DC converter 3-12volt voltage and $1200 \mathrm{~mA}$ current. Data calibration generator view at table 1. Interpolation

$y=206.4 x+3.10-13$

a. Second step, Building KERS simple prototype consep show at figure 1.

b. Third step, Building KERS simple prototype actualize for prototype view at figure 2 .

c. Fourth step, Analysis kinetic energy recovery for braking (Mechanical KERS).

d. Angular Velocity $=206.4 \times$ v (volt $)+3 \times 10-13$ (rpm)

e. $\quad$ Convertion $\mathrm{rpm}$ to $\mathrm{rad} / \mathrm{s}=\mathrm{rpm} \times 2 \pi / 60(\mathrm{rad} / \mathrm{s})$

f. Kinetic Energy $=0.5 \times$ I x $\omega 2$ (Joule), $\omega=\mathrm{rad} / \mathrm{sec}$ 
g. Fifth step, Charging test for mode Acceleration and deceleration and observasion charging Mechanical Electrical KERS.

\section{RESULT AND DISCUSSION}

The faster rotation braking shortly before the longer it will span generated by the flywheel to continue the generation that wasted energy, in the experiment produced the early rounds before braking $2766 \mathrm{rpm}$ with a duration of $26.8 \mathrm{~s}$. To determine the resulting kinetic energy generation flywheel then be tested against the setting with set points VSD $10 \mathrm{~Hz}, 15 \mathrm{hz}, 20 \mathrm{hz}$ and $25 \mathrm{hz}$ as speed just before braking. Of the test results obtained graph results braking process and the length of time the mechanical KERS kinetic energy which can be seen in table 2. While the magnitude of the kinetic energy can be observed in the figure $3 \mathrm{a}-3 \mathrm{~d}$.

To determine the performance of KERS is made, the first analysis performed on the magnitude of deceleration flywheel speed variation when performed just before braking. The magnitude of deceleration can be seen in Table 2 that can be taken a picture that the larger a given round before the duration of the braking energy resurrection will be getting longer, but the smaller the value of deceleration. The second analysis is the amount of force produced by the flywheel which is obtained from the calculation of kinetic energy obtained when the process is carried out divided by the long duration of the braking energy resurrection. Calculation results can be seen in Table 3 which states that given the large round just before braking the greater the kinetic energy generated, while the mechanical power will also be greater. The third form of the results of the analysis of observations made of the electrical energy produced by the generator is used for battery charging process can be seen in Figure 4. Of acceleration or deceleration conditions KERS turns magnitude of voltage and electric current does not change significantly with the results in Table 4 with 14.07 volt of voltage, current and power of electric 5.078A 71.3 watt. That is because the generator used is equipped with a regulator IC that allows you to adjust the amount of voltage and electric currents are done for the battery charging process.

Mechanical-electrical KERS characteristics at acceleration and deceleration with VSD settings 10hz, $15 \mathrm{hz}, 20 \mathrm{hz}, 25 \mathrm{hz}$ and braking did not affect the magnitude of the voltage or electric current is generated, but the old generation influenced energy generator loading process. Based on observations made on the process 50Ah 12volt battery charging, electrical mechanical KERS apparently capable of producing an average voltage 14.07 volt, the average current and power 5.078Ampere average electrical energy 71.3 watt.
The fourth analysis is to compare the power output of the generator mechanical power produced by the flywheel rotation. Calculation results can be seen in Table 5 which states that the highest efficiency is obtained from giving input on the shortly rotasion variable speed drive (VSD) setting that produces $10 \mathrm{~Hz}$ $1197 \mathrm{rpm}$ rotation with an efficiency of $119 \%$. So on the condition that ensures that the round city vehicle in a high intensity with engine speed between 1000-2000rpm is often done braking. So with just too frequent braking energy is wasted eating very large, to harness the wasted energy that it needs to be modified conventional braking system or ABS with the addition of KERS system that is able to generate due to the braking kinetic energy into electrical energy that will be used again for the purposes of related to automotive technology.

\section{CONCLUSION}

Mechanical electrical KERS characteristics acceleration and deceleration with VSD settings 10hz, $15 \mathrm{hz}, 20 \mathrm{hz}, 25 \mathrm{hz}$ and braking did not affect the magnitude of the voltage or electric current is generated, but the old generation influenced energy generator loading process. Based on observations made on the process 50Ah 12 volt battery charging, electrical mechanical KERS apparently capable of producing an average voltage 14.07 volt, the average current 5.078Ampere and average electrical power energy 71.3watt.

\section{REFERENCES}

[1]. Afonso, J.L et all (2012), "On the potential of regenerative braking of electric buses as a function of their itinerary", EWGT 2012 15th meeting of the EURO Working Group on Transportation, Centro Algoritmi, University of Minho, Guimarães, Portugal, Procedia Science Direct, Social and Behavioral SciencesVol. 54, page. 1156-1167.

[2]. Cibulka, J. (2009), "Kinetic Energy Recovery System By Means Of Flywheel Energy Storage", Advanced Engineering, ISSN 1846-5900, Vol 3(1) page. 27-38.

[3]. Jaferson, C. M. dan Ackerman, M. (1996), "a Flywheel Variator Energy Storage System", Energy Convers, Faculty of Engineering, University of the West of England, Frenchay Campus, Coldharbour Lane, Bristol BSI6 IQY, U.K. MGMT Vol.37, No.10, page.1481-1491.

[4]. Liu, H. dan Jiang, J. (2008), "Flywheel Energy Storage-An Upswing Technology For Energy Sustainability", School of Mechatronics Engineering, Harbin Institute of Technology, Harbin, Heilongjiang Province, China, Science Direct, Energy and Buildings Vol.39 page. 599-604.

[5]. Mantriota J. dkk, (2012), "Mechanical hybrid KERS based on toroidal traction drives: an example of smart tribological design to improve terrestrial vehicle performance", University of Surrey, Faculty of Engineering and Physical Sciences, Guildford, UK, page. 1-14.

[6]. Pimsarn, M. dkk (2011), "Design of Regenerative Braking System for an Electric Vehicle (EV) Modified from Used Car", ETM19 The Second TSME International Conference on Mechanical Engineering. 


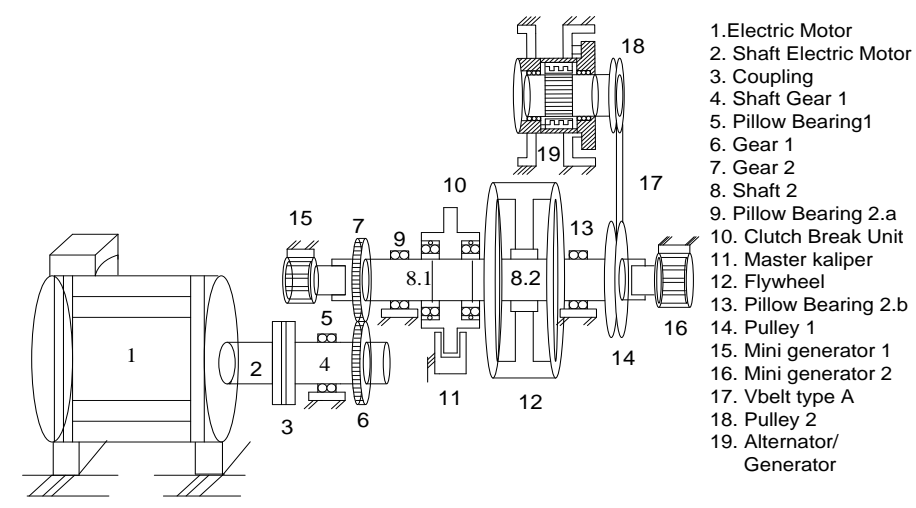

Figure 1. Concept prototype

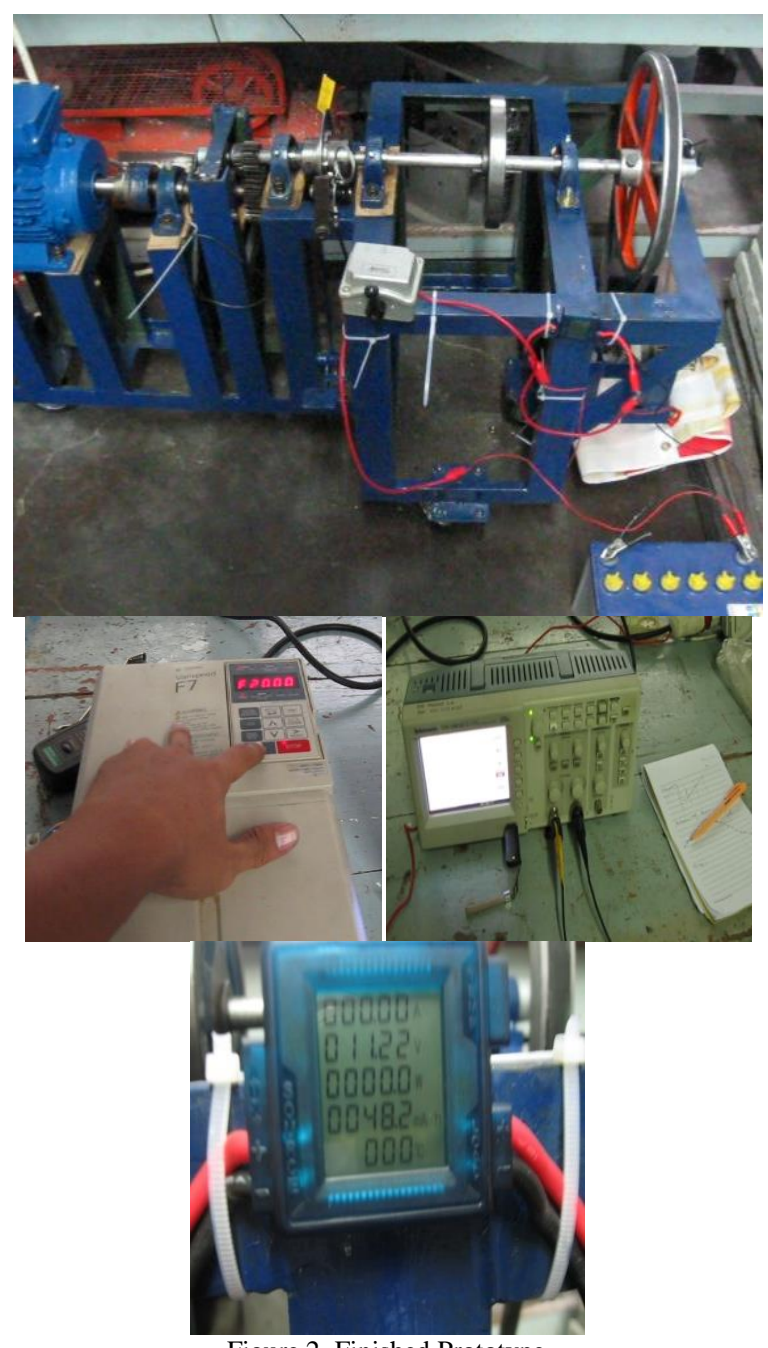

Figure 2. Finished Prototype 
Flywheel Energy Storage System From VSD 10hz

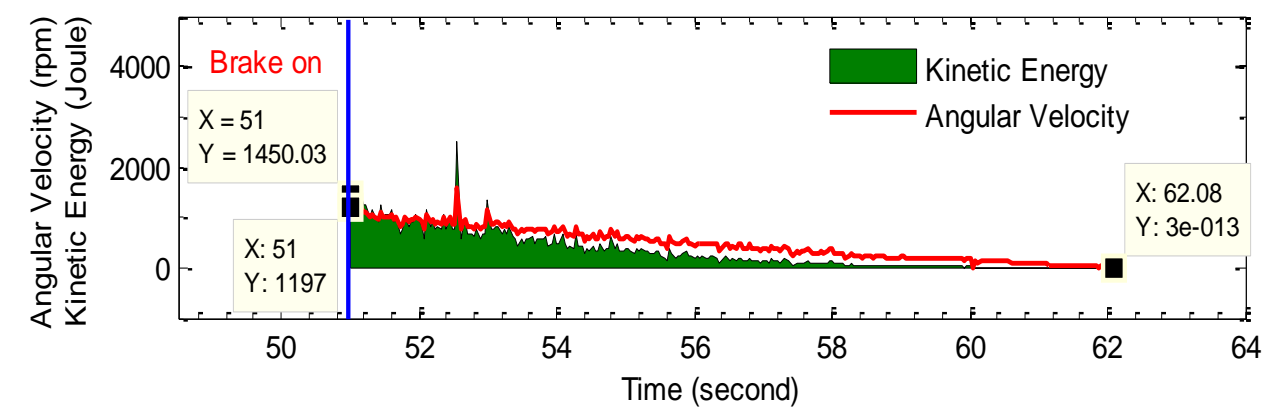

Flywheel Energy Storage System From VSD 15hz

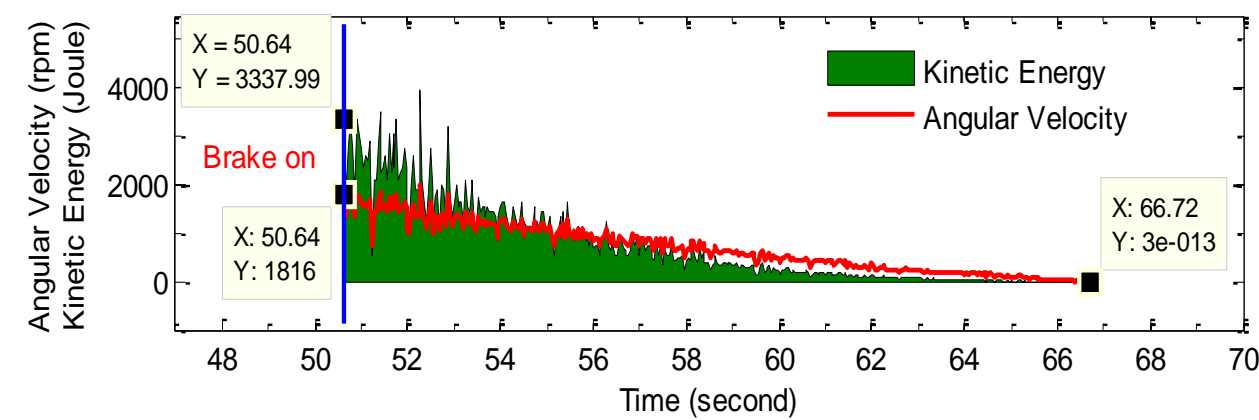

Flywheel Energy Storage System From VSD 20hz

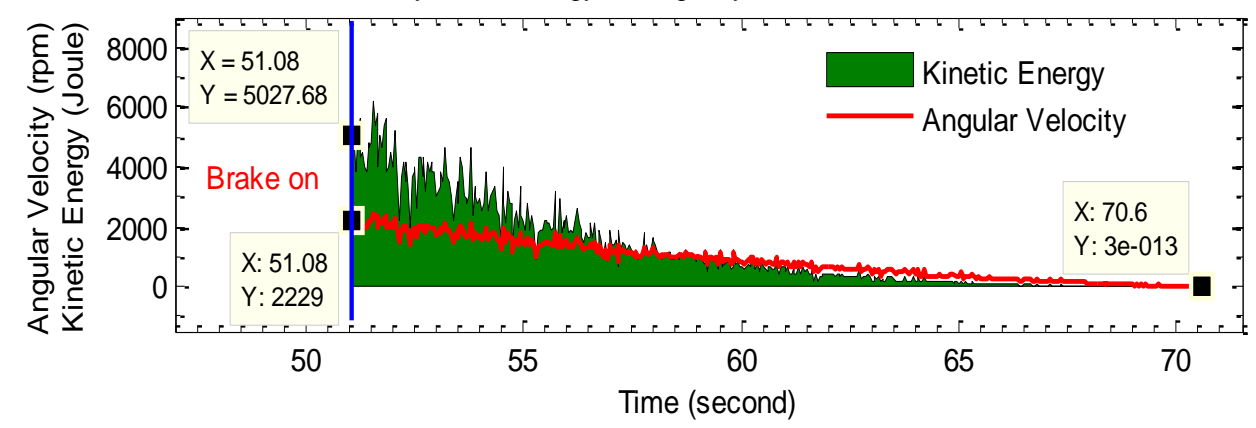

Flywheel Energy Storage System From VSD 25hz

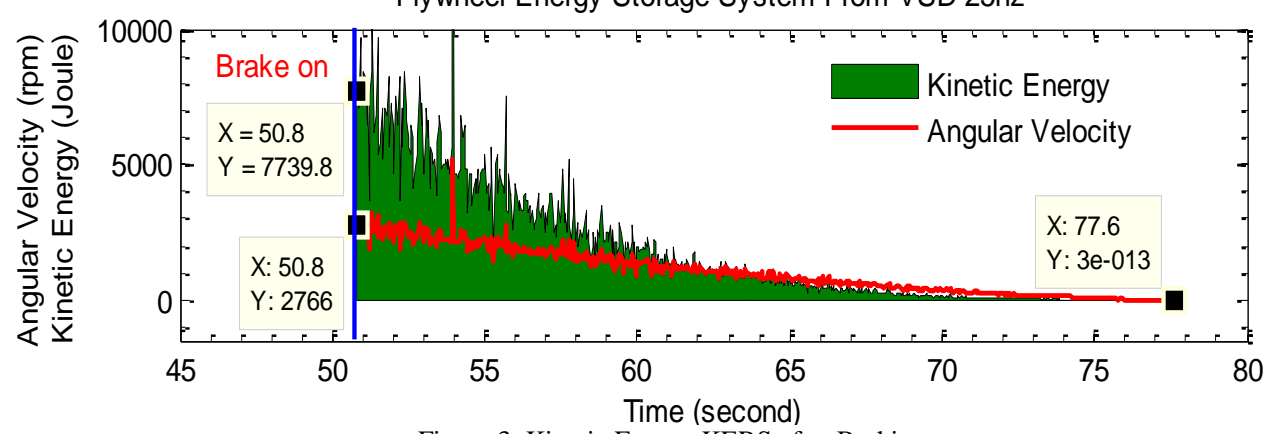

Figure 3. Kinetic Engery KERS after Braking on 


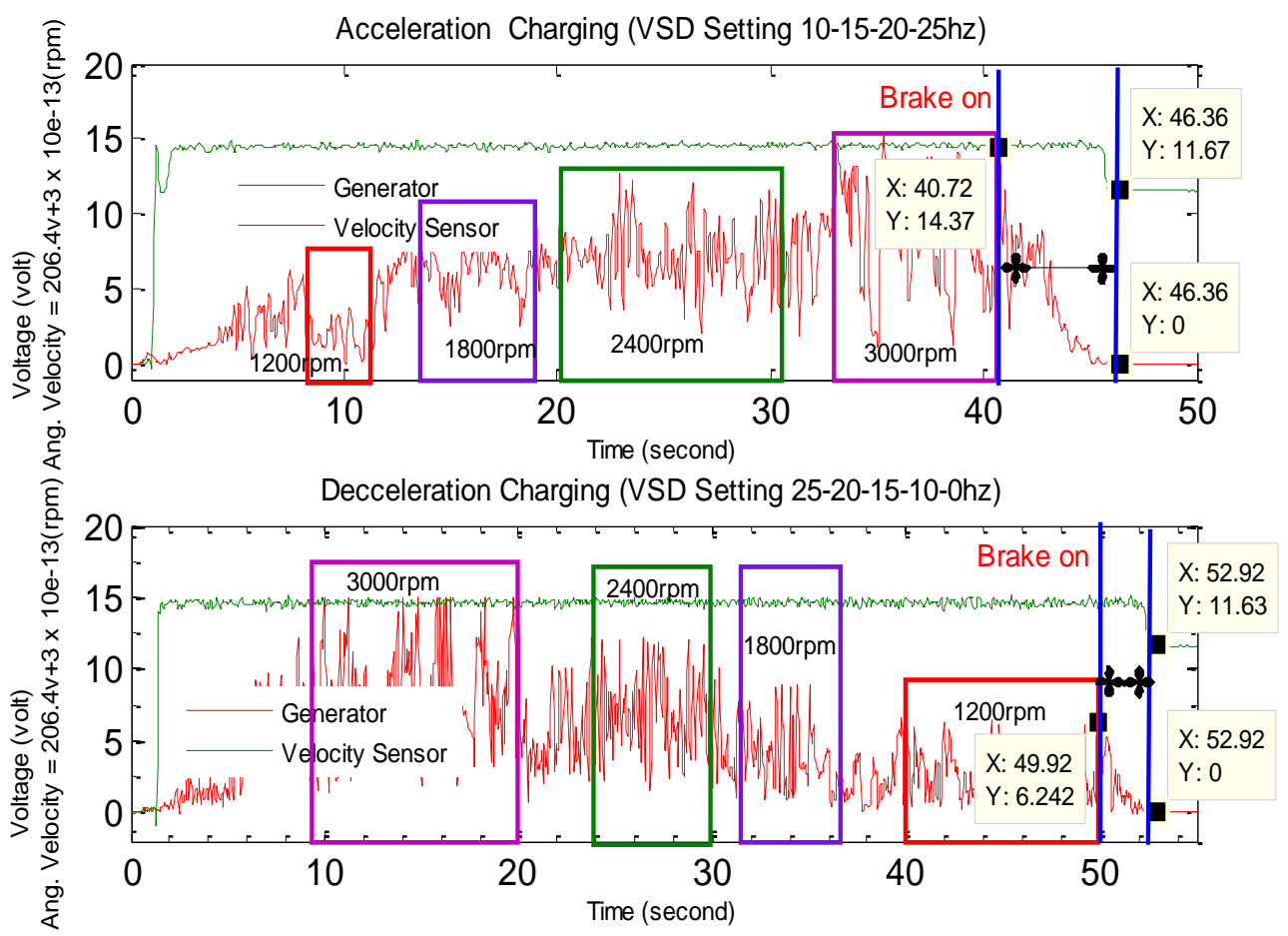

Figure 4. Voltage and Angular Velocity KERS at acceleration and Deceleration Condition

TABLE 1.

INTERPOLATION

\begin{tabular}{rc}
\multicolumn{2}{c}{ INTERPOLATION } \\
\hline \hline Voltage & AV $(\mathrm{rpm})$ \\
\hline 5.14 & 1061 \\
5.20 & 1064 \\
7.36 & 1068 \\
7.42 & 1619 \\
7.48 & 1621 \\
7.54 & 1629 \\
9.70 & 1632 \\
9.76 & 2161 \\
9.82 & 2163 \\
9.88 & 2168 \\
11.98 & 2170 \\
12.04 & 2705 \\
12.10 & 2707 \\
14.15 & 2712 \\
14.21 & 3240 \\
14.26 & 3242 \\
14.32 & 3248 \\
\hline \hline
\end{tabular}

TABLE 2.

DECELERATION FLYWHEEL

\begin{tabular}{lllllll}
\hline \hline $\begin{array}{l}\text { VSD } \\
(\mathrm{Hz})\end{array}$ & $\mathrm{t} 1$ & $\mathrm{t} 2$ & $\Delta \mathrm{t}$ & $\begin{array}{l}\text { Theta } \\
(\mathrm{rpm})\end{array}$ & $\begin{array}{l}\text { Theta } \\
(\mathrm{rad} / \mathrm{s})\end{array}$ & $\begin{array}{l}\text { Deceleration } \\
\left(\mathrm{rad} / \mathrm{sec}^{2}\right)\end{array}$ \\
\hline 10 & 51 & 62.08 & 11.08 & 1197 & 125.29 & 11.31 \\
15 & 50.64 & 66.72 & 16.08 & 1816 & 190.07 & 11.82 \\
20 & 51.08 & 70.6 & 19.54 & 2229 & 233.30 & 11.94 \\
25 & 50.8 & 77.6 & 26.8 & 2766 & 289.51 & 10.80 \\
\hline \hline
\end{tabular}


TABLE 3

POWER MECHANICAL

\begin{tabular}{|c|c|c|c|c|c|c|}
\hline $\begin{array}{l}\text { Set poin } \\
(\mathrm{hz})\end{array}$ & \multicolumn{3}{|c|}{$\begin{array}{l}\text { Angular } \\
\text { Velocity (rpm) }\end{array}$} & $\begin{array}{l}\text { Kinetic } \\
\text { Energy }(J)\end{array}$ & $\begin{array}{l}\text { Duratio } \\
\mathrm{n} \text { (secon } \\
\text { d) }\end{array}$ & $\begin{array}{l}\text { Power } \\
\text { Mechanica } \\
1 \text { (Watt) }\end{array}$ \\
\hline 10 & \multicolumn{3}{|c|}{1197} & 663.22 & 11.08 & 59.86 \\
\hline 15 & \multicolumn{3}{|c|}{1816} & 1526.35 & 16.08 & 94.92 \\
\hline 20 & \multicolumn{3}{|c|}{2229} & 2299.62 & 19.54 & 117.69 \\
\hline 25 & \multicolumn{3}{|c|}{2766} & 3541.23 & 26.8 & 132.14 \\
\hline \multicolumn{7}{|c|}{$\begin{array}{c}\text { TABLE } 4 . \\
\text { POWER ELECTRICAL } \\
\end{array}$} \\
\hline $\begin{array}{l}\text { Set } \\
(\mathrm{hz})\end{array}$ & poin & \multicolumn{2}{|c|}{$\begin{array}{l}\text { Tegangan } \\
\text { (volt) }\end{array}$} & Arus (A) & \multicolumn{2}{|c|}{ Power (Watt) } \\
\hline 10 & \multicolumn{3}{|c|}{14.07} & 5.078 & 71.3 & \\
\hline 15 & \multicolumn{3}{|c|}{14.07} & 5.078 & 71.3 & \\
\hline 20 & \multicolumn{3}{|c|}{14.07} & 5.078 & 71.3 & \\
\hline 25 & \multicolumn{3}{|c|}{14.07} & 5.078 & 71.3 & \\
\hline \multicolumn{7}{|c|}{$\begin{array}{c}\text { TABLE } 5 . \\
\text { EFFICIENCY KERS } \\
\end{array}$} \\
\hline $\begin{array}{l}\text { Set poin } \\
(\mathrm{hz})\end{array}$ & \multicolumn{2}{|c|}{$\begin{array}{l}\text { Teganga } \\
\text { n (volt) }\end{array}$} & $\begin{array}{l}\text { Arus } \\
\text { (A) }\end{array}$ & $\begin{array}{l}\text { Power } \\
\text { Electric } \\
\text { (Watt) }\end{array}$ & $\begin{array}{l}\text { Power } \\
\text { Mechanic } \\
\text { al (Watt) }\end{array}$ & $\begin{array}{l}\text { Efisien } \\
\text { si }(\%)\end{array}$ \\
\hline 10 & \multicolumn{2}{|c|}{14.07} & 5.078 & 71.3 & 59.86 & 119 \\
\hline 15 & \multicolumn{2}{|c|}{14.07} & 5.078 & 71.3 & 94.92 & 75 \\
\hline 20 & \multicolumn{2}{|c|}{14.07} & 5.078 & 71.3 & 117.69 & 60 \\
\hline 25 & \multicolumn{2}{|c|}{14.07} & 5.078 & 71.3 & 132.14 & 53 \\
\hline
\end{tabular}

